\title{
Influence of natamycin loading methods on the physical characteristics of alginate active films
}

\author{
Andrea C.K. Bierhalz ${ }^{a}$, Mariana A. da Silva ${ }^{a}$, Hermínio C. de Sousa ${ }^{b}$, Mara E.M. Braga ${ }^{\text {, } *}$, \\ Theo G. Kieckbusch ${ }^{\mathrm{a}, * *}$ \\ a DEMBio, School of Chemical Engineering, University of Campinas, UNICAMP, Av. Albert Einstein 500, 13083-852 Campinas, SP, Brazil \\ b CIEPQPF, Chemical Engineering Department, FCTUC, University of Coimbra, Rua Silvio Lima, Pólo II - Pinhal de Marrocos, 3030-790 Coimbra, Portugal
}

\section{A R T I C L E I N F O}

Article history:

Received 26 December 2012

Accepted 28 January 2013

\section{Keywords:}

Active biofilms

Alginate

Natamycin

Supercritical solvent impregnation

Controlled release

\begin{abstract}
A B S T R A C T
Natamycin, an antimicrobial agent sparingly soluble in water, was incorporated into alginate films in order to produce antimicrobial packaging, using three different approaches: the conventional loading method, when natamycin is added directly to the polymeric aqueous film-forming solution; the immersion procedure, by which a previously prepared films is contacted with natamycin solution, and by the supercritical solvent impregnation (SSI) method, with loading tests performed in $\mathrm{CO}_{2}$ containing natamycin, with and without addition of cosolvent (ethanol, $10 \%$ molar). The loading capacities were evaluated, as well as the influence on physical attributes of the films and on the release behavior of natamycin in water. The conventional method led to films heterogeneities with high surface roughness, and the immersion technique evinced several disadvantages like low incorporation yields, and negative influence on water vapor permeability and on the swelling degree of the film. The supercritical method showed that longer contact times and the use of ethanol as a cosolvent increased the natamycin loading yields and led to homogeneous films, where $\mathrm{SSI}\left(\mathrm{CO}_{2}+\mathrm{EtOH}\right)$ process produced visually attractive and tranlucent films.
\end{abstract}

(c) 2013 Elsevier B.V. All rights reserved.

\section{Introduction}

The increasing consumer demand for food products with less additives has intensified the research on antimicrobial packaging. In this innovative concept of food protection, antimicrobial agents are incorporated into polymeric films and can be slowly released onto the food surface, where deterioration by microbial growth more intensively begins. The controlled release of the active agent allows the maintenance of the critical concentration necessary for inhibiting the microbial growth and, consequently, the quantity of additives added to the product is reduced [1,2]. In addition, antimicrobial packaging is an alternative method to overcome limitations of the direct addition of preservants in the food formulations, like the reduction of their antimicrobial potential due to reactions and/or complexation with food system components [3].

Biodegradable films prepared from polysaccharide materials, such as alginate, can control moisture, gases and lipid migration and can also act as carriers for antimicrobials agents. Hence, antimicrobial biodegradable film is an attractive alternative to

\footnotetext{
* Corresponding author.

** Corresponding author. Tel.: +55 1935213930.

E-mail addresses: marabraga@eq.uc.pt (M.E.M. Braga), theo@feq.unicamp.br (T.G. Kieckbusch).
}

enhance food safety, while simultaneously protect the environment $[4,5]$.

Alginates are hydrophilic polysaccharides produced from brown algae (Phaeophyceae). Chemically, they are linear copolymers of $(1,4)$-linked $\beta$-D-mannuronate (M) and $\alpha$-L-guluronate $(G)$ units, which are arranged as homopolymeric blocks (poly-M and poly$\mathrm{G}$ ) and blocks with an alternating sequence. The use of alginates presents advantages due to their availability, biodegradability and ability to form water insoluble and resistant films by crosslinking with divalent ions, especially calcium [6].

A wide range of antimicrobial substances have been studied in order to evaluate their potential application in antimicrobial biodegradable films. These substances include organic acids (sorbates, benzoic acids), bacteriocins (nisin, pediocin), enzymes (lysozyme), natural extracts (garlic oil, rosemary extract, propolis, etc.) and fungicides $[5,7,8]$. Each antimicrobial substance exhibits a specific mechanism of action against a particular class of microorganisms [2]. Natamycin is a natural antifungal agent produced by the bacterium Streptomyces natelensis during fermentation and is widely used in the food industry for the prevention of mold contamination in meats and cheeses [9]. This compound is approved by the Food and Drug Administration (FDA) as a food additive and classified as GRAS (Generally Regarded As Safe). Natamycin was also assigned as a natural preservative by the European Union [7]. 
The direct application of natamycin on food surfaces by spraying, dipping or coating has shown questionable results due to unsuitable adherence and also because the diffusion into the bulk of the food will reduce the surface concentration [10,11]. Furthermore, the maximum natamycin concentration at the surface of final products should be $1 \mathrm{mg} / \mathrm{dm}^{2}$ and it should not be detectable at $2 \mathrm{~mm}$ depth $[10,12]$. The use as active films wrappings could be more efficient, by maintaining a critical concentration on the food surface and preventing its migration or loss [11].

Active biofilms are usually prepared by the direct loading method, adding the antimicrobial to the film-forming solution, containing biopolymer, plasticizer and cross-linkers. However, due to the large molecular weight and the conjugated double bond structure, natamycin has very low water solubility $(0.052 \mathrm{mg} / \mathrm{mL})$ and the films obtained by this method are usually opaque and heterogeneous [12]. The poor distribution of the active agent in the film matrix may also cause changes in the structure and in the functional attributes of the films. Effects on the barrier and mechanical properties of biopolymers films were reported by several studies [13-15].

The incorporation of hydrophobic substances into polymeric matrices can also be conducted by the immersion/soaking technique, where previously prepared films are immersed into a solution containing the active substance and, alternatively, by the Supercritical Solvent Impregnation (SSI) method [16].

The SSI has recently attracted attention in the preparation of controlled-release drug delivery systems, especially in ophthalmic and anti-inflammatory formulations [16-18]. Applications of this new technique in antimicrobial packaging are quite scarce [19]. Supercritical fluid, like carbon dioxide, at conditions near or above their critical temperature and pressure, exist as a single phase that has the unique ability to diffuse through solids like a gas and to dissolve materials like a liquid. By this method, the supercritical fluid swells the polymeric matrix, increasing the free molecular volume, allowing the active agent to diffuse into the structure. After depressurization, the supercritical solvent can be completely removed from the polymer matrix, and no degradation of additives and biopolymers is observed. The load of the active agent can be increased by controlling the depressurization rate, by changing the impregnation period or by varying the solvent density by pressure and temperature manipulation [18]. Besides achieving a more efficient incorporation of lipophilic active agents, the SSI method can also increase the flexibility of the film, since treatments with supercritical carbon dioxide were able to plasticize certain polymers, resulting in a decrease of the glass transition temperature of the matrix [20].

In this work, alginate based films containing natamycin as active agent were prepared by the conventional loading, by immersion and by the supercritical carbon dioxide impregnation/deposition methods. The three processes were compared in terms of loading yield and release behavior of natamycin. In the immersion and in the supercritical solvent loading method, the effects of processing time and of ethanol addition on the natamycin loading efficiency were also evaluated. Processed and non-processed samples were characterized by FTIR spectroscopy, thickness, drop contact angle, water vapor permeability, water uptake, mechanical resistance, surface roughness, color and micro-morphology.

\section{Materials and methods}

\subsection{Materials}

Medium viscosity sodium alginate (Sigma-Aldrich, St. Louis, USA) extracted from Macrocystis pyrifera seaweed with an average molecular mass of $1.61 \times 10^{6} \mathrm{Da}$, was used as structural matrix of the films. Calcium chloride dihydrate (Merck, Darmstadt, Germany) was the crosslinking agent and glycerol (Synth, Diadema, Brazil) was the plasticizer. Natamycin (Natamax ${ }^{\circledR}, 50 \% \mathrm{w} / \mathrm{w}$ purity), kindly donated by Danisco (São Paulo, Brazil), was used as antimicrobial agent. Carbon dioxide (99.998\%, Praxair, Spain) and ethanol (Panreac, Spain) were used as solvent.

\subsection{Film preparation}

Alginate films were made by casting in a two-stage crosslinking procedure. In the first stage, a film forming solution of the biopolymer $(1.5 \mathrm{~g} / 100 \mathrm{~mL}$ ) was prepared in $400 \mathrm{~mL}$ distilled water already containing $0.6 \mathrm{~g}$ glycerol/g biopolymer at room temperature. The solution was mechanically stirred at $900 \mathrm{rpm}$ (Tecnal, TE-139, Piracicaba, Brazil) for about $1 \mathrm{~h}$ to ensure homogeneity. Afterwards, the temperature of the system was raised to $70^{\circ} \mathrm{C}$ and a dilute aqueous calcium chloride solution $\left(30 \mathrm{~mL}, 0.27 \% \mathrm{Ca}^{2+}\right.$ $\mathrm{w} / \mathrm{v}$ ) was slowly added to the biopolymer solution at a flow rate of $1 \mathrm{~mL} / \mathrm{min}$ delivered by a peristaltic pump (Masterflex C/L, model 77120-70, Vernon Hills, USA). Aliquots of the solution ( $50 \mathrm{~mL}$ ) were poured into square plexiglas ${ }^{\circledR}$ frames $\left(225 \mathrm{~cm}^{2}\right)$ and dried in a convection oven (Fanem, model 099EV, Guarulhos, Brazil) at $40^{\circ} \mathrm{C}$ for about $20 \mathrm{~h}$. After detaching the resulting film from the support, the crosslinking was complemented with a second contact stage, by total immersion of the films in $50 \mathrm{~mL}$ of an aqueous calcium solution $(1.2 \% \mathrm{w} / \mathrm{v})$ containing glycerol $(3 \% \mathrm{v} / \mathrm{v})$ for $20 \mathrm{~min}$. The excess of liquid on the surface was removed and the films were dried in a ventilated ambient for about $5 \mathrm{~h}$, at room temperature [21]. All films were conditioned at room temperature and 52\% relative humidity inside desiccators for 3 days before submission to physical characterization. These films were considered as control films.

\subsection{Natamycin loading}

\subsubsection{Conventional loading}

The conventional active films were prepared as described previously, but $4 \mathrm{~g}$ natamycin/100 $\mathrm{g}$ alginate was added to the polymeric solution containing calcium chloride (first stage). The system was further stirred for another $10 \mathrm{~min}$ before casting. According to da Silva et al. [22], this amount of natamycin represents a compromise between adequate film packaging attributes and effective antimycotic action.

\subsubsection{Loading by immersion in natamycin aqueous solutions}

Samples cut from the alginate films, with $9 \mathrm{~cm}^{2}$ area, were immersed in $20 \mathrm{~mL}$ aqueous solution containing ethanol $(1,2,3,5$ and $8 \%$, molar), glycerol $(3 \% \mathrm{w} / \mathrm{v})$ and natamycin $(0.1 \% \mathrm{w} / \mathrm{v})$ at room temperature $\left(23 \pm 1^{\circ} \mathrm{C}\right)$ under low magnetic stirring. Preliminary tests indicate that the natamycin was not completely dissolved in the lower ethanol concentration solution. In order to evaluate the influence of contact time on total mass of natamycin loading, films were kept immersed for 2, 5, 10, 18 and $24 \mathrm{~h}$. After the immersion period, the films were placed on plexiglas ${ }^{\circledR}$ frames and dried at room temperature for $24 \mathrm{~h}$ and then conditioned at $52 \% \mathrm{RH}$.

\subsubsection{Supercritical solvent impregnation}

The supercritical solvent impregnation was performed in a batch apparatus composed by a stainless steel impregnation cell (with approximately $20 \mathrm{~cm}^{3}$ of internal volume), a magnetic stirring plate and a compressed air operated $\mathrm{CO}_{2}$ liquid pump as described in the literature [16,17], modified to a thermostatically controlled air bath. Ethanol (EtOH, 10\% mol) was used as cosolvent with the purpose of increase natamycin solubility in supercritical carbon dioxide. Square samples cut from the films with $1 \mathrm{~cm}^{2}$ area were previously weighed and fitted in supports which were placed 
inside the high-pressure cell that already contained natamycin $\left(2 \mathrm{mg}\right.$ ) in EtOH. Different $\mathrm{scCO}_{2}$ densities (from 628 to $830 \mathrm{~kg} / \mathrm{m}^{3}$ ) were also evaluated in preliminary tests, however the lowest densities showed low incorporation yields and therefore higher density, which corresponds to a process conditions of $40^{\circ} \mathrm{C}$ and $20 \mathrm{MPa}$, was maintained for further assays. Magnetic stirring was maintained in order to solubilize the natamycin and to homogenize the supercritical fluid mixture. Experiments were carried out during 2.5, 4 and $14 \mathrm{~h}$ in order to assess the influence of the contact time on the loading mass of natamycin. After the processing period, the $\mathrm{CO}_{2}$ or the mixture of $\mathrm{CO}_{2}$ and EtOH were removed by slow depressurization $(0.5 \mathrm{MPa} / \mathrm{min})$ in order to avoid damages of the processed films. The film samples were re-conditioned at $52 \%$ RH before characterization.

\subsection{Natamycin quantification}

The amount of natamycin loaded in the alginate films was determined by dissolving films samples (about $8 \mathrm{mg}$ ) in $5 \mathrm{~mL}$ of a $2 \%$ sodium citrate solution. The natamycin concentration was obtained using a UV/VIS spectrophotometer (Jasco, model 530, Japan) with readings at $319 \mathrm{~nm}[11]$. Each determination was performed in triplicate.

\subsection{Natamycin release}

Natamycin release tests were performed in duplicate by immersing square samples of loaded films $\left(1 \mathrm{~cm}^{2}\right)$ in $5 \mathrm{~mL}$ milliQ water under magnetic agitation ( $100 \mathrm{rpm})$ at a temperature of $25^{\circ} \mathrm{C}$. At pre-determined time periods, an aliquot $(2.0 \mathrm{~mL})$ of the solution was removed, analyzed and then returned into the sink medium. This procedure was repeated until equilibration. The natamycin concentration in water was determined using spectrophotometer at $319 \mathrm{~nm}$. The mean film thickness was determined before and after each experiment.

\subsection{Diffusion coefficient determination}

Diffusion coefficients were determined from the experimental release test data using the analytical relationship derived from the solution to Fick's Second Law for a flat plate [23]. Under the conditions of the experiments, assuming that the concentration of natamycin in the sink solution remains close to zero and a constant total film thickness, $\delta$, Eq. (1) can be used for the fractional natamycin release.

$\frac{M_{t}}{M_{\infty}}=1-\frac{8}{\pi^{2}} \sum_{n=0}^{\infty} \frac{1}{(2 n+1)^{2}} \exp \left(-(2 n+1)^{2} \frac{\pi^{2} D}{\delta^{2}} t\right)$

where $M_{t}$ and $M_{\infty}$ are the mass of the diffusant released from the film at time $t$ and at infinite time, respectively, $\delta$ is the film thickness measured at the end of the test and $D$ is the effective diffusivity of natamycin in the film matrix, assumed constant.

For short contact times, when less than $60 \%$ of the solute mass is liberated, a simplified solution of Fick's Second Law can be used (Eq. (2)):

$\frac{M_{t}}{M_{\infty}}=4 \sqrt{\frac{D t}{\delta^{2} \pi}}$

The mechanism involved in the diffusion process for a planar system was investigated by fitting the early portion of the release curve $\left(M_{t} / M_{\infty}<0.60\right)$ to the following Power Law Model (Eq. (3)) [23].

$\frac{M_{t}}{M_{\infty}}=k t^{n}$ where $k$ is a kinetic constant that characterizes the macromolecular arrangement of the polymer matrix, $t$ is the release time and $n$ is a diffusional exponent that typifies release mechanisms.

\subsection{Film characterization}

\subsubsection{Thickness}

The thickness of the conditioned films was measured with a digital micrometer (0.001 mm, model MDS-25S, Mitutoyo, Japan) at three random positions.

\subsubsection{Contact angle}

The contact angle of a drop of water placed on the film surface were measured using the sessile drop method $(10 \mu \mathrm{L})$ in an OCA20 contact angle apparatus (Dataphysics Instruments, Germany). Six replicates for each film were performed.

\subsubsection{Water uptake, WU}

Water uptake measurements were carried out on processed and non-processed films, in triplicate. Film samples $\left(1 \mathrm{~cm}^{2}\right)$ were weighed and immersed in distilled water $\left(25^{\circ} \mathrm{C}\right)$ under agitation until equilibration [24]. During this period, at different time intervals, the swollen films were removed from the bath, placed between two dry filter papers to remove residual liquid from the film surface, reweighed and returned to the water. The water uptake was calculated as the mass fraction increase relative to the initial mass.

\subsubsection{Fourier-transform infrared spectroscopy (FTIR)}

FTIR-ATR spectroscopy of the films was performed using a spectrometer (Jasco, model 4000, UK) at 128 scans and with $4 \mathrm{~cm}^{-1}$ resolution, between 400 and $4000 \mathrm{~cm}^{-1}$. Films without natamycin were also evaluated as control.

\subsubsection{Color}

Hunter color parameters were measured by a colorimeter Minolta (Model CT-310, Osaka, Japan). Control films (without natamycin) were used as standard to calculate the total color difference.

\subsubsection{Thermogravimetric analysis (TGA)}

The water content and degradation temperature of the alginate films were obtained by thermogravimetric analysis in a TGA Q500 (TA Instruments, New Castle, USA). Samples with about $6 \mathrm{mg}$ were processed over a temperature range of $25-600^{\circ} \mathrm{C}$ at a scan rate of $10^{\circ} \mathrm{C} / \mathrm{min}$. Tests were conducted, in duplicate, under a nitrogen gas purge $(100 \mathrm{~mL} / \mathrm{min})$.

\subsubsection{Water vapor permeability (WVP)}

The water vapor permeability coefficient of the films was determined gravimetrically at $25^{\circ} \mathrm{C}\left( \pm 1^{\circ} \mathrm{C}\right)$ according to ASTM method E96-95 [25]. Film samples were sealed over a circular opening of a small glass permeability cell $\left(10 \mathrm{~cm}^{3}\right)$ filled with anhydrous calcium chloride, maintaining a stagnant air gap of less than $1 \mathrm{~mm}$ below the film. These cells were kept in hermetically closed chambers $\left(500 \mathrm{~cm}^{3}\right)$ containing a saturated solution of sodium chloride at $25^{\circ} \mathrm{C}$ in order to maintain a $\mathrm{RH}$ difference of $75 \%$. The salt solution in the bottom was occasionally agitated through a magnetic stirrer. The cell weight was measured at pre-determined time periods for 3 days using an analytical balance. The WVP was calculated using Eq. (4). Determinations were made in triplicates.

$\mathrm{WVP}=\frac{G \cdot \delta}{A \cdot \Delta R H \cdot P_{w}}$

where $\delta$ is the film average thickness ( $\mathrm{mm}), G$ is the permeation rate ( $\mathrm{g} /$ day) calculated by linear regression of the mass gain versus 

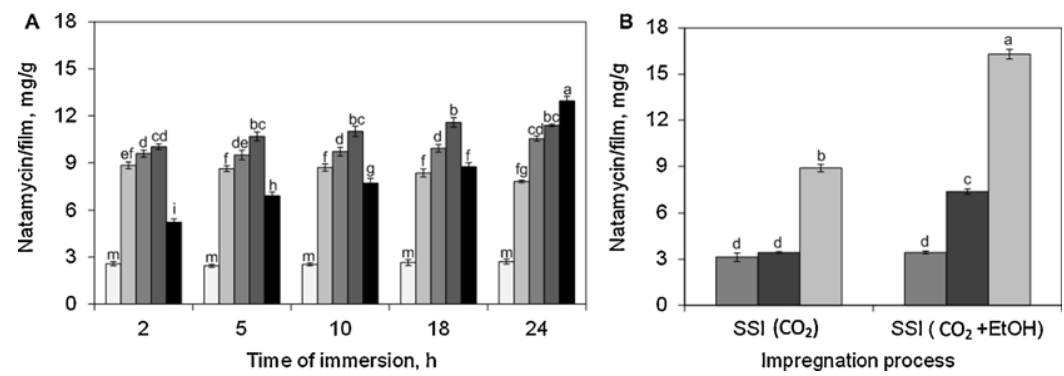

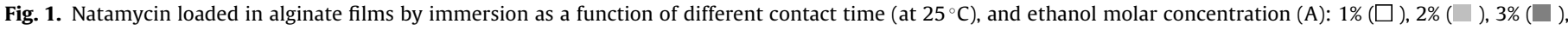

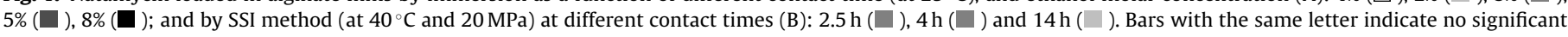
differences $(p<0.05)$.

time, $A$ is the permeation area $\left(0.785 \mathrm{~cm}^{2}\right)$, DRH is the difference in relative humidity $(0.75)$ and $P_{\mathrm{w}}$ is the partial water vapor pressure at test temperature $(3.167 \mathrm{kPa})$.

\subsubsection{Mechanical properties}

Tensile strength (TS) and elongation at break $(E)$ of the preconditioned films were determined at room temperature using a TA.XT2 texturometer (Stable Microsystems SMD, Surrey, UK) according to ASTM standard method D882 [26]. Films were cut into strips $(10 \times 2.54 \mathrm{~cm})$ and fixed between the corrugated grips of the instrument. The initial grip spacing and the cross-head speed were set at $5 \mathrm{~cm}$ and $0.1 \mathrm{~cm} / \mathrm{s}$, respectively. Measurements were taken in an ambient of $25^{\circ} \mathrm{C}$ and $55 \pm 5 \% \mathrm{RH}$, with at least 8 repetitions. The tensile strength was expressed as the maximum force at break per initial cross-sectional area of the film and the elongation as a percentage of the original length. Film samples processed with supercritical $\mathrm{CO}_{2}$ without natamycin impregnation were also submitted to the texturometer in order to evaluate the effect of $\mathrm{scCO}_{2}$ processing on the mechanical properties. Samples loaded with natamycin by this method could not be evaluated due to inappropriate dimensions.

\subsubsection{Roughness}

The surface roughness of the films was determined using a portable rugosimeter (Mitutoyo, SJ-210, Japan) with cutoff set in $0.8 \mathrm{~mm}$ and total length in $5 \mathrm{~mm}$. Measurements were performed on both sides of the film, at least three times for each sample film. All results given are the average of triplicate samples measurements.

\subsubsection{Morphology}

The surface and cross-section morphology of the films was observed by scanning electron microscopy (SEM) (LEO Electron Microscopy, model LEO440i, UK) at $15 \mathrm{kV}$. Film samples were fixed on the stub and then sputter coated with gold (approximately $92 \AA$ ) to enhance surface conductivity.

\subsection{Statistical analysis}

Analysis of Variance and Tukey Test were used to determine statistically significant differences $(p<0.05)$ among averages, using the Software Statistica V.1.1.5.

\section{Results and discussion}

Alginate films containing natamycin incorporated through the Supercritical Solvent Impregnation (SSI), as well as by the immersion method were homogeneous, transparent and visually attractive, though samples processed by SSI presented apparently dryer surfaces. Films loaded by the conventional loading method were perceptibly heterogeneous, with a rough surface and showed a hazier appearance. All films were easily removed from the frames and showed adequate flexibility.

\subsection{Natamycin uptake}

Samples of alginate films were immersed in natamycin ethanol/water solutions (from 1 to $8 \%$, molar) for different time periods. The total mass of natamycin uptake for each case is given in Fig. 1A. The results indicate different equilibration rates, according to the amount of ethanol in the solution. With only $1 \%$ (molar) the equilibrium is attained in less than $2 \mathrm{~h}$, but it takes more than $24 \mathrm{~h}$ when in contact with $8 \%$ (molar) ethanol solution. This behavior can be explained by the swelling/structure relaxation promoted by water and was also observed by $\mathrm{Xu}$ et al. [24] for alginatecarrageenan hydrogel. According to these authors, the trend toward reduced swelling with increasing ethanol concentration can be attributed to the increasing osmotic pressure of the medium and a consequent reduction in the quantity of water entering the film matrix.

The striking increase in loading when the ethanol concentration was increased from $1 \%$ to $2 \%$ is due to incomplete solubilization of natamycin at lower ethanol concentration. The results suggest a wide range of condition that could be selected as appropriate for an efficient loading. Since the amount of natamycin was not strongly affected above $5 \%$ ethanol and $5 \mathrm{~h}$ of immersion time, this condition was selected as representative, as a compromise of film swelling and shorter contact time.

SSI using different $\mathrm{scCO}_{2}$ densities were also evaluated in preliminary tests (from 628 to $830 \mathrm{~kg} / \mathrm{m}^{3}$ ), however the lowest densities $\left(628\right.$ and $780 \mathrm{~kg} / \mathrm{m}^{3}$ ) showed low incorporation yields (3.9 and $10.9 \mathrm{mg}$ natamycin/g film, respectively) and therefore higher density $\left(830 \mathrm{~kg} / \mathrm{m}^{3}\right)$ was maintained for further assays $(16.3 \mathrm{mg}$ natamycin $/ g$ film). Fig. 1B shows the natamycin uptake using the SSI with and without EtOH (10\%, molar) as cosolvent and for 3 different contact periods. The results indicate that the amount of natamycin loaded increases sharply by increasing the processing time, and that the presence of ethanol (10\%, molar) strongly influences the impregnation. Natamycin exhibits an amphipathic nature being easily solubilized by strongly polar organic solvents. The chain that contains the two hydroxyl groups has hydrophilic and hydrophobic characteristics, whereas the chain with four double bonds is completely hydrophobic [27]. As ethanol is polar and soluble in $\mathrm{scCO}_{2}$, its addition in small amounts as cosolvent can increase the overall polarity of the $\mathrm{scCO}_{2}$ mixture and, consequently, the solubility of polar substances is enhanced [17]. In addition, the low cosolvent amount allows to maintain the solvent mixture as an homogeneous phase and under supercritical state. Longer processing time improves the drug loading yield, probably due to lower $\mathrm{scCO}_{2}$ diffusion into this polymeric matrix.

Table 1 compares the concentration of natamycin incorporated by the films at the selected conditions evaluated in this study. The 
Table 1

Total amount of natamycin into alginate films at the different loading methods and samples characterization.

\begin{tabular}{|c|c|c|c|c|c|}
\hline \multirow[t]{2}{*}{ Characterization } & \multirow[t]{2}{*}{ Control $^{\mathrm{a}}$} & \multicolumn{4}{|c|}{ Loading method } \\
\hline & & Conventional $^{\mathrm{a}}$ & Immersion $^{\mathrm{a}}$ & $\operatorname{SSI}\left(\mathrm{CO}_{2}\right)^{\mathrm{a}}$ & $\mathrm{SSI}\left(\mathrm{CO}_{2}+\mathrm{EtOH}\right)^{\mathrm{a}}$ \\
\hline Total natamycin/film (mg/g) & - & $17.74 \pm 1.20 \mathrm{a}$ & $10.68 \pm 0.29 b$ & $8.89 \pm 0.24 c$ & $16.29 \pm 0.31 a$ \\
\hline Thickness $(\mu \mathrm{m})$ & $31 \pm 1.9 a$ & $31 \pm 2.7 \mathrm{a}$ & $28 \pm 0.8 \mathrm{a}$ & $28 \pm 0.3 a$ & $29 \pm 1.9 a$ \\
\hline Roughness ( $\mu \mathrm{m})$ & $0.13 \pm 0.03 c$ & $0.44 \pm 0.06 a$ & $0.26 \pm 0.06 b$ & $0.22 \pm 0.03 b$ & $0.19 \pm 0.04 b c$ \\
\hline Contact angle $\left(^{\circ}\right)$ & $47.1 \pm 3.5 c$ & $69.6 \pm 5.1 \mathrm{a}$ & $72.3 \pm 4.7 \mathrm{a}$ & $54.4 \pm 2.4 b$ & $57.8 \pm 2.9 b$ \\
\hline Color difference, $\Delta E$ & - & $4.71 \pm 0.11 \mathrm{a}$ & $2.70 \pm 0.08 b$ & $1.61 \pm 0.03 c$ & $1.55 \pm 0.05 c$ \\
\hline Water vapor permeability, WVP & $3.67 \pm 0.17 c$ & $4.05 \pm 0.07 b$ & $6.10 \pm 0.13 a$ & $4.31 \pm 0.06 b$ & $4.11 \pm 0.23 b$ \\
\hline Water uptake, WU ( $\mathrm{g} \mathrm{H}_{2} \mathrm{O} / \mathrm{g}$ film) & $0.66 \pm 0.01 b$ & $0.54 \pm 0.05 c$ & $0.76 \pm 0,03 a$ & $0.59 \pm 0.04 \mathrm{cb}$ & $0.60 \pm 0.02 \mathrm{cb}$ \\
\hline Tensile strength, TS (MPa) & $112.2 \pm 7.26 a$ & $94.1 \pm 5.42 b$ & $97.8 \pm 5.74 b$ & $87.9 \pm 3.91 \mathrm{~b}^{\mathrm{b}}$ & $90.2 \pm 2.75 \mathrm{~b}^{\mathrm{b}}$ \\
\hline Elongation at break, $\mathrm{E}(\%)$ & $5.07 \pm 0.79 b$ & $5.38 \pm 0.69 b$ & $7.55 \pm 0.16 a$ & $2.67 \pm 0.56 \mathrm{c}^{\mathrm{b}}$ & $2.99 \pm 0.25 \mathrm{c}^{\mathrm{b}}$ \\
\hline First derivative of the weight loss, $\mathrm{DTG}_{1}\left({ }^{\circ} \mathrm{C}\right)$ & $246.6 \pm 0.4 a$ & $237.1 \pm 0.3 b$ & $250.3 \pm 1.2 \mathrm{a}$ & $248.7 \pm 1.4 \mathrm{a}$ & $249.1 \pm 1.5 \mathrm{a}$ \\
\hline First derivative of the weight loss, $\mathrm{DTG}_{2}\left({ }^{\circ} \mathrm{C}\right)$ & $415.3 \pm 0.8 b$ & $416.1 \pm 0.4 b$ & $434.5 \pm 2.9 \mathrm{a}$ & $418.1 \pm 1.8 b$ & $411.7 \pm 1.7 b$ \\
\hline Weight loss at $100^{\circ} \mathrm{C}(\%)$ & $11.8 \pm 1.4 \mathrm{~b}$ & $12.2 \pm 1.3 \mathrm{~b}$ & $15.4 \pm 0.2 \mathrm{a}$ & $13.4 \pm 1.0 \mathrm{~b}$ & $12.5 \pm 0.8 b$ \\
\hline Residue at $600^{\circ} \mathrm{C}(\%)$ & $37.8 \pm 0.5 a$ & $35.0 \pm 0.8 b$ & $35.4 \pm 0.2 b$ & $37.2 \pm 0.5 a$ & $37.7 \pm 0.2 \mathrm{a}$ \\
\hline
\end{tabular}

a Average \pm standard deviation of experimental determinations, averages with the same letter, in the same line, indicate no statistically significant differences $(p<0.05)$.

b Results for supercritical treated films, without natamycin impregnation.

mass of natamycin present in the final film is important to their antimicrobial efficiency. In vitro experiments have shown that the amount of natamycin obtained by conventional method, as well as by the $\mathrm{SSI}\left(\mathrm{CO}_{2}+\mathrm{EtOH}\right)$ technique ( $14 \mathrm{~h}$ of processing) would be adequate to provide antimicrobial effect against molds and yeasts $[12,22]$. In this way, the contact period between alginate films and drug/solvent for $14 \mathrm{~h}$ using the SSI method was selected for further studies. Films drug loaded by the immersion method retain an amount of natamycin similar to that observed in films processed by SSI technique (without ethanol).

The solubility of natamycin in $\mathrm{scCO}_{2}$ is not known, but probably the incorporation yield could be increased by using purified natamycin. The commercial natamycin used in this work is composed of $50 \%$ lactose (water soluble), which may influence the solubility of the product in $\mathrm{scCO}_{2}$.

\subsection{Morphology}

SEM micrographs of the surfaces and cross-sections of loaded and non-loaded films are shown in Fig. 2. Control films exhibited a very homogeneous structure. Natamycin loaded by conventional method caused changes on the film surface, with non-uniform distribution of the antimicrobial and even the presence of crystals was observed. This results from the limited solubility of natamycin in the solution that formed the film and a consequent second phase formation during the film drying. The presence of antimicrobial crystals detected by SEM were also observed in cellulose films containing natamycin and nisin [14], in cellulose films containing pediocin [28] and in methyl cellulose and wheat gluten films containing natamycin [29].

Micrographs of films processed by the immersion method also show crystals at the surface, but in smaller quantities. On the other hand, the micrographs of films processed by SSI technique, with ethanol as cosolvent, exhibited a structure similar to the control films, without crystals at the surfaces. These observations confirmed the good drug loading and probably the micronization of natamycin in the films structure.

\subsection{Physical attributes of films}

Since the incorporation of antimicrobials, as well as the method of drug loading affected the microstructure, active films were submitted to physical characterization procedures and the results compared to the natamycin-free film (control film). The values of thickness, roughness, contact angle and total color difference of alginate films are shown in Table 1 .
The results indicate that, statistically, the thickness of the films did not significantly change with the presence of natamycin and also with the different loading processes. Film thickness is an important parameter for packaging films and usually influences attributes such as water vapor permeability, mechanical properties and release of active agents.

The roughness values are related to the surface irregularities captured in the SEM micrographs. The roughness is higher for the sample obtained by conventional drug loading method and decreases following the order: conventional drug loading < immersion $<$ SSI $\left(\mathrm{CO}_{2}\right)<$ SSI $\left(\mathrm{CO}_{2}+\mathrm{EtOH}\right)<$ control film. The increase of film surface roughness after incorporation of lipidic and hydrophobic compounds was also observed in other studies [30]. The roughness effect probably is due to the low drug solubility, where the incorporated natamycin crystallizes during films finishing procedures and confirms that the supercritical impregnation can be used as an alternative method for homogeneous solute uptake distribution due to its micronization abilities [31].

The contact angle measurement evaluates the hydrophobic or hydrophilic characteristics of a film surface. High contact angle $\left(\theta>70^{\circ}\right)$ indicates a hydrophobic surface and low values $\left(\theta<20^{\circ}\right)$ are characteristics of hydrophilic surfaces. As expected, results show that the presence of natamycin in the films leads to higher contact angle, signalizing that the tendency to absorb water is decreased and that the surfaces became more hydrophobic. These results are in agreement with the findings of roughness, which can be directly related to contact angle [32]. Among the different methods of drug loading, immersion and conventional loaded films show significantly higher contact angle values compared to the other two conditions. These observations were also identified in the SEM micrographs as described before. The contact angle value found for the control films (without natamycin) was different compared to the range reported in the literature for alginate films and coatings [33,34].

Transparency and color are important for films intended for food packaging since its appearance will influence consumer acceptance of the product. The data in Table 1 show that the total color difference $(\Delta E)$, calculated using the control films as standard, was lower for films processed by the SSI techniques (with and without co-solvent), indicating that these films have an aspect very similar to the control films. This result, as well as the roughness data also confirms that the SSI technique allows a more homogeneous impregnation by natamycin.

The values of water vapor permeability (WVP) of the different films are also shown in Table 1 . The addition of natamycin caused a significant increase $(p<0.05)$ of the permeability coefficient for all loading conditions. Several studies on active films have reported 

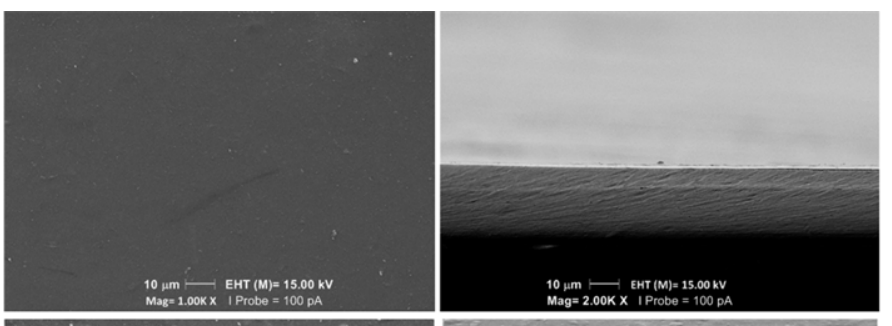

Control
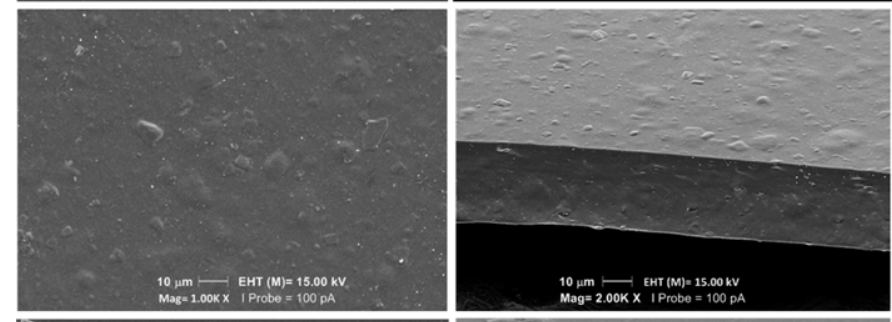

Conventional
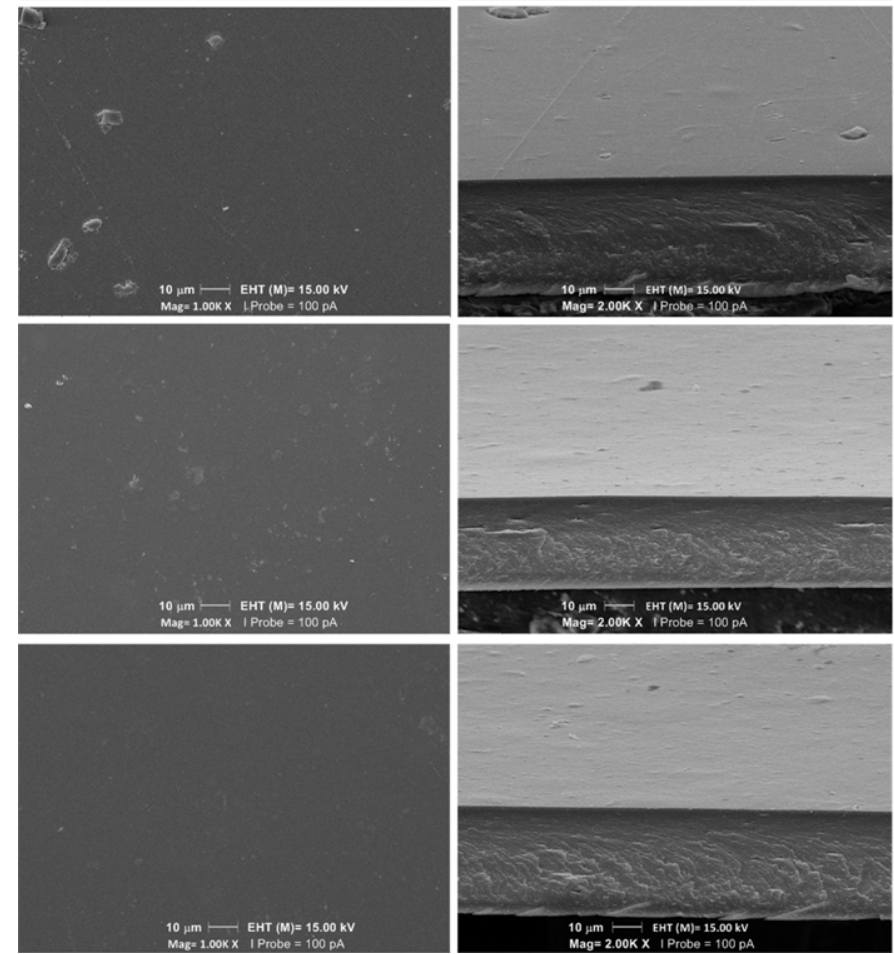

$\mathrm{SSI}\left(\mathrm{CO}_{2}+\mathrm{EtOH}\right)$

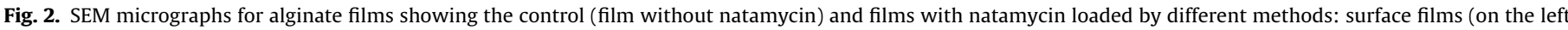
side) and films cross section (on the right side).

an increase in WVP with the addition of the antimicrobial agent, attributable to micro or macro heterogeneities in the polymeric structure $[13,35]$. The data in Table 1 indicate that WVP of the films loaded by immersion was higher $(p<0.05)$ compared to the conventional method and the films processed by the two SSI techniques. This behavior could be attributed to an increase in glycerol content in the films after the immersion process. Glycerol was added to the immersion solution in order to prevent its leaching from the original 2nd stage formed films. Long contact time allows higher glycerol uptake, over-plasticizing the film and increasing the free volume within the polymeric structure, which enhances permeability [36].

Control and active films were submitted to water uptake tests in contact with distilled water at $25^{\circ} \mathrm{C}$ and the values obtained at equilibrium are listed in Table 1 . The equilibrium of alginate films in water is quickly attained (after about $5 \mathrm{~min}$ ) as already reported by Bierhalz et al. [21] and da Silva et al. [35]. The general trend found parallels the behavior of water vapor permeability pointing out that the immersion procedure renders films with the highest uptake of water mass. This feature reinforces the hypothesis that the film became more plasticized after the contact with glycerol. Films processed by the SSI techniques presented water uptake values equivalent to the control and to the conventional films.

Tensile strength (TS) and elongation at break (E) of the control and active films are also presented in Table 1 . The presence of natamycin and/or used loading processes may cause a significant reduction $(p<0.05)$ in the tensile strength compared to the control films, but the overall conclusions should be considered with care, since the SSI treated films did not contain natamycin and these results are only due to the $\mathrm{scCO}_{2}$ effect on the polymeric matrix. A loss in the mechanical resistance may be attributed to modifications in the polymeric macro-structure, when the excess of antimicrobial agent was not properly incorporated [4,37]. Similar behavior was observed by Pires et al. [14] in cellulose films with natamycin and by Cha and Chinnan [38] studying alginate films containing nisin. The different loading processes did not affect greatly the tensile 

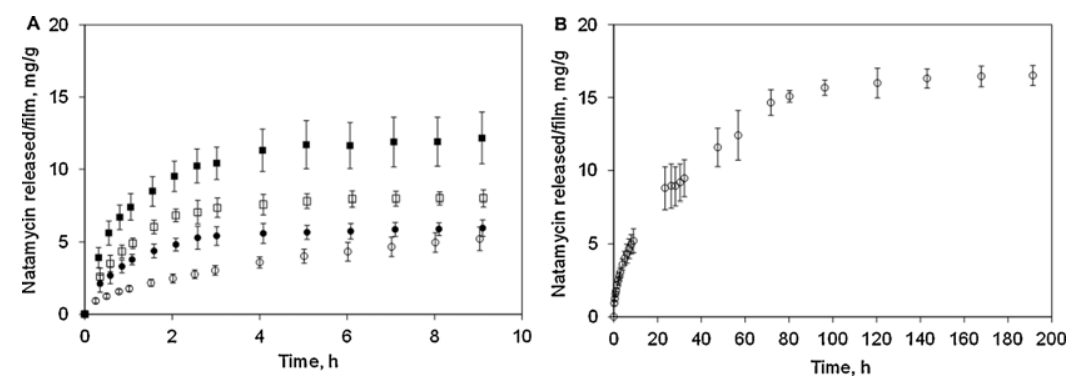

Fig. 3. Accumulated natamycin mass released from alginate films loaded by $\mathrm{SSI}\left(\mathrm{CO}_{2}+\mathrm{EtOH}\right)$ (A) and until the equilibrium (B)

strength (reduction of 13-21\%), but exerted strong influence on the elongation at break. The plasticity of films exposed to a supercritical fluid environment was significantly lower (reduction of 41 and $47 \%$ ) compared to the control. It can be assumed that a fraction of the glycerol and/or moisture, existing in the initial film was extracted by the supercritical fluid during processing, which probably leads to an increase in the glass transition temperature and, therefore in a decrease in the elongation of the films. On the other hand, films loaded by immersion presented the highest elongation at break (increase of $49 \%$ ). These findings complement the list of evidences that point out to an increase of glycerol and water content in the immersed process film. As already stated by da Silva et al. [36], a comparison between the mechanical properties data in Table 1 confirms that variations in the plasticizer concentration can exert an substantial effect on film elongation, but only a moderate effect on tensile strength.

The thermal stability of alginate films was assessed by TGA and the results are showed in Table 1 . Two steps of degradation were observed for all conditions. The first degradation occurred at $227-249{ }^{\circ} \mathrm{C}$, followed by a second inflection at $414-436^{\circ} \mathrm{C}$. The first temperature range reflexes the decomposition of alginate by dehydration of the saccharide rings, breaking up of $\mathrm{C}-\mathrm{H}$ bonds and breaking of the $\mathrm{C}-\mathrm{O}-\mathrm{C}$ glycosidic bonds in the main chain of the polysaccharides; the second degradation temperature corresponds to formation of carbonaceous materials [39]. Literature reports similar degradation temperatures for alginate films [40]. The addition of natamycin by conventional method anticipated the thermal stability temperature of the film by $10^{\circ} \mathrm{C}$. Drug loading by immersion and SSI did not alter the degradation temperature.

\subsection{Natamycin release in water}

Fig. 3 shows the accumulated natamycin mass released from alginate films loaded by different methods. A comparison between release curves of natamycin from the alginate films samples indicates that the event was much slower in films loaded by conventional method. The natamycin release from films processed by immersion and by SSI technique (with and without EtOH) reached equilibrium in $4-5 \mathrm{~h}$, while this period increased to approximately $140 \mathrm{~h}$ for conventional films (Fig. 3B). The total amount of natamycin released for each film $\left(M_{\infty}\right)$ is shown in Table 2 and is statistically similar to the natamycin loaded to each film (Table 1) confirming that all mass added to the films can be released.

As described before, films obtained by conventional loading method contain more crystals dispersed in the polymeric structure (observed by SEM, Fig. 2). As the crystals first need to be dissolved in order to migrate to the water, the release kinetic is repressed [15]. The reduced particle size in films processed by SSI technique increased the total surface area and also may have contributed through the Gibbs-Thomson effect to reduce the formation of crystals. In several studies, the micronization of substances, mainly poor water soluble drugs, using $\mathrm{CO}_{2}$ supercritical have been used as alternative to increase the solubility by reducing the particle size without the use of organic solvents [31].

Effective diffusion coefficients of natamycin from alginate films were estimated by adjusting the experimental data to Eq. (1) using 15 terms in the sum. Initial experimental data $\left(M_{t} / M_{\infty}<0.6\right)$ were also adjusted to the diffusion model for short contact times (semiinfinite solid model) using Eq. (2). These values, the total time of release as well as the determination coefficient $\left(R^{2}\right)$ found for each situation are shown in Table 2.

As expected, the diffusivity coefficients are very low for the conventional processed films, however the higher diffusion coefficient found for films processed by SSI suggests that the natamycin micronization was really promoted by this method, which contributed to the improvement of its release rate. For the entire kinetic release curve, samples processed by $\mathrm{SSI}\left(\mathrm{CO}_{2}\right)$ and $\mathrm{SSI}\left(\mathrm{CO}_{2}+\mathrm{EtOH}\right)$ presented the diffusion coefficient $D_{1}$ higher than immersion processed ones, $\sim 49 \%$ and $34 \%$ respectively. In the same way, the first portion of kinetic release curve (short time) also presented a $D_{2}$ higher for SSI processed samples ( $88 \%$ and $48 \%$ for $\operatorname{SSI}\left(\mathrm{CO}_{2}\right)$ and $\mathrm{SSI}\left(\mathrm{CO}_{2}+\mathrm{EtOH}\right)$ respectively) when compared to immersion values. This confirms that SSI promoted reduction of the drug particle size and indicates that water uptake and structure relaxation

Table 2

Total natamycin released mass, diffusion coefficients ( $D_{1}$ and $\left.D_{2}\right)$ estimated by fitting Eqs. (1) and (2), and natamycin release kinetic parameters by fitting Eq. (3).

\begin{tabular}{|c|c|c|c|c|}
\hline \multirow[t]{2}{*}{ Diffusion coefficients and drug release kinetic parameters } & \multicolumn{4}{|c|}{ Loading method } \\
\hline & Conventional & Immersion & $\operatorname{SSI}\left(\mathrm{CO}_{2}\right)$ & $\mathrm{SSI}\left(\mathrm{CO}_{2}+\mathrm{EtOH}\right)$ \\
\hline Total mass of natamycin released, $M_{\infty}$ (g/gfilm) & $16.51 \pm 0.69$ & $6.65 \pm 0.23$ & $8.13 \pm 0.21$ & $14.06 \pm 0.93$ \\
\hline Time, $t_{\infty}(\mathrm{h})$ & 191.4 & 30.2 & 6.1 & 23.4 \\
\hline Diffusion coefficients $\left(D_{1}\right)$ from Eq. $(1)\left(\mathrm{cm}^{2} / \mathrm{s} \times 10^{10}\right)$ & 0.164 & 1.06 & 2.06 & 1.43 \\
\hline Determination coefficient $\left(R_{D_{1}}^{2}\right)$ & 0.9991 & 0.9673 & 0.9883 & 0.9744 \\
\hline Diffusion coefficients $\left(D_{2}\right)$ from Eq. $(2)\left(\mathrm{cm}^{2} / \mathrm{s} \times 10^{10}\right)$ & 0.181 & 1.30 & 2.45 & 1.93 \\
\hline Determination coefficient $\left(R_{D_{2}}^{2}\right)$ & 0.9987 & 0.9932 & 0.9965 & 0.9882 \\
\hline Diffusion exponent $(n)$ from Power Law Equation Eq. (3) & 0.50 & 0.57 & 0.57 & 0.52 \\
\hline Diffusional constant $(k)\left(\times 10^{3}, \mathrm{~s}^{-1}\right)$ & 1.8 & 5.0 & 5.3 & 5.0 \\
\hline Determination coefficient $\left(R^{2}\right)$ & 0.9986 & 0.9943 & 0.9954 & 0.9917 \\
\hline
\end{tabular}


have a limited influence on the mechanism involved in the diffusion process [41], since the drug diffusion in the release assays were performed in the same medium.

Although the diffusivity was higher for films processed by SSI technique, the observed values were at least two orders of magnitude lower compared to published data on release of antimicrobial agents. Values of diffusivity of sorbic acid are in the order of $10^{-6} \mathrm{~cm}^{2} / \mathrm{s}$ in alginate films [42] and $10^{-8}$ in wheat gluten films [43]. For whey protein films, values found for potassium sorbate are in the order of $10^{-7} \mathrm{~cm}^{2} / \mathrm{s}$ [44]. Sodium benzoate diffusivities are in the order of $10^{-8} \mathrm{~cm}^{2} / \mathrm{s}$ in polyvinylalcohol [45].

Knowledge of the release rate and, therefore, of the diffusivity of the active agents from the film matrix into the food is a determinant factor in the development of antimicrobial films [41]. Controlled release of the active agent is desirable in order to maintain a concentration that inhibits deteriorating reactions on food surfaces, thus assuring safety and quality levels during storage [46]. A rapid release may cause migration of the active agent to internal parts of the food, reducing the protection at the surface [1]. Alternatively, if the release rate is very slow, its inhibitory concentration cannot be reached. In this way, natamycin release rate should be tested in a final product to experiment how slow the drug should migrate to the food surface, in order to protect the product during the storage period.

Diffusion exponents of the Power Law Model (Eq. (3)) were obtained by plotting $\ln \left(M_{t} / M_{\infty}\right)$ versus $\ln (t)$. As shown in Table 2 , conventional films presented a diffusional exponent $(n)$ equal to 0.5 , indicating that Fickian diffusion is the predominant mechanism and release rate will depend on $t^{0.5}$. These results also confirm that the major part of the diffusion process takes place on the already swollen film. Films processed by immersion and by the two SSI techniques presented a diffusional exponent between 0.5 and 1 , but still very close to 0.5 . These films tend to show a slight anomalous diffusion, a mechanism in which the diffusion rate of the solvent and the relaxation of the polymeric chains are of the same order of magnitude. The deviation from Fickian behavior indicates that the polymer relaxation phenomenon is more prominent and may affect the release of natamycin during the first moments of the process.

An anomalous diffusion mechanism was also observed by Zactiti and Kieckbusch [41] for alginate films with potassium sorbate and Ozdemir and Floros [44] during release of potassium sorbate from whey protein films. The diffusional kinetic constant $(k)$ was lower for conventional films, which is consistent with the diffusion coefficients and time to total release values found.

\subsection{FTIR and TGA}

The FTIR-ATR spectra of processed and non-processed alginate films are shown in Fig. 4. Peaks around 3230, 1598, 1418, and $1025 \mathrm{~cm}^{-1}$ can be observed, attributable to $\mathrm{O}-\mathrm{H}, \mathrm{COO}-$ (asymmetric), $\mathrm{COO}-$ (symmetric), and $\mathrm{C}-\mathrm{O}-\mathrm{C}$ stretching of alginate, respectively [47]. No relevant changes occurred in any of the characteristic structural peak of films after natamycin loading. Peaks around 3500 to $3300 \mathrm{~cm}^{-1}$ are also attributed to $\mathrm{N}-\mathrm{H}$ stretch, characteristic of natamycin, and probably were overlapped by $\mathrm{O}-\mathrm{H}$ peaks. For films processed by immersion, bands close to $2940 \mathrm{~cm}^{-1}$ that correspond to the $\mathrm{C}-\mathrm{H}$ stretching vibration shifted to lower wavenumbers $\left(2920 \mathrm{~cm}^{-1}\right)$ and bands of $\mathrm{O}-\mathrm{H}$ shifted to higher numbers $\left(3270 \mathrm{~cm}^{-1}\right)$. According to Cerqueira et al. [48], the increase of glycerol concentration can be responsible for this behavior. These findings are additional evidences that in the loading by the immersion process, films are prone to contain higher glycerol content.

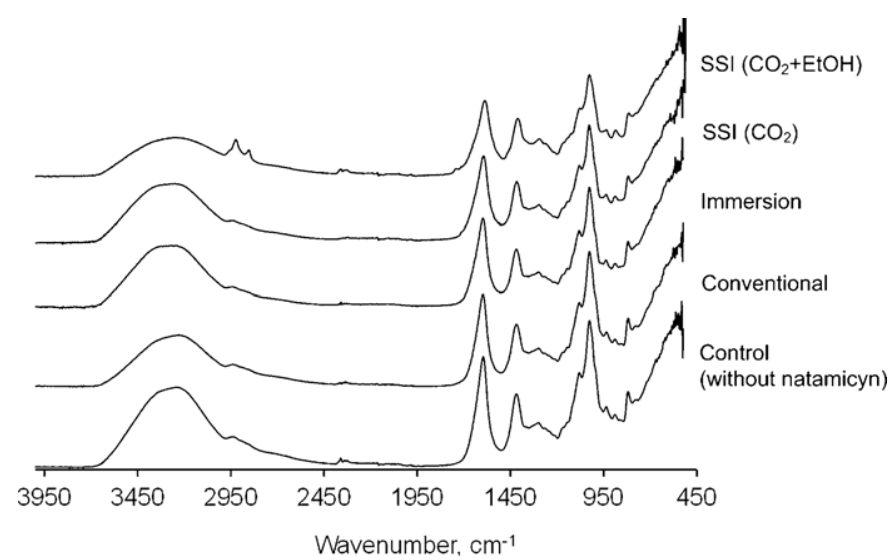

Fig. 4. FTIR-ATR spectra of natamycin loaded and of non-loaded alginate films

\section{Conclusions}

The three methods of natamycin loading in alginate films generate active films with complementary characteristics. Conventional method is the simplest and usual practice. It produces strong structures with low water vapor permeability and good controlled release qualities during longer period $(\sim 140 \mathrm{~h})$. However, the films tend to be translucent and with a rough surface due to natamycin crystallization.

Loading by immersion in a natamycin/ethanol/water/glycerol solution proved to be dependent of the ethanol concentration and contact time leading to inefficient natamycin incorporation. The immersion solution composition needs to be optimized in order to avoid glycerol uptake with negative influence on the water vapor permeability and water uptake.

The $\mathrm{SSI}\left(\mathrm{CO}_{2}+\mathrm{EtOH}\right)$ produced visually attractive films (translucent and dry) with natamycin loading capacity similar to conventional method, probably due to natamycin micronization during the process. Despite of the use of ethanol (10\% molar), samples processed by SSI $\left(\mathrm{CO}_{2}+\mathrm{EtOH}\right)$ presented adequate water vapor permeability and higher active solute release rate, but reduced mechanical properties (mainly the elongation). Drug solution composition also could be optimized in order to avoid glycerol and water extraction during the SSI process.

The results presented in this work show that alginate films loaded with natamycin may be used as antimicrobial packaging, since they have good properties and can be processed by different loading methods without loss of its main properties.

\section{Acknowledgments}

The authors acknowledge the CAPES and CNPq for financial support.

\section{References}

[1] P. Appendini, J.H. Hotchkiss, Review of antimicrobial food packaging, Innovative Food Science and Emerging Technologies 3 (2002) 113-126.

[2] L. Bastarrachea, S. Dhawan, S.S. Sablani, Engineering properties of polymericbased antimicrobial films for food packaging, Food Engineering Reviews 3 (2011) 79-93.

[3] S. Gemili, A. Yemenicioglu, S.A. Altinkaya, Development of cellulose acetate based antimicrobial food packaging materials for controlled release of lysozyme, Journal of Food Engineering 90 (2009) 453-462.

[4] J.H. Han, Antimicrobial food packaging, Food Technology 54 (2000) 56-65.

[5] C.A. Campos, L.N. Gerschenson, S.K. Flores, Development of edible films and coatings with antimicrobial activity, Food and Bioprocess Technology 4 (2011) 849-875.

[6] Y. Fang, S. Al-Assaf, G.O. Phillips, K. Nishinari, T. Funami, P.A. Williams, Binding behavior of calcium to polyuronates: comparison of pectin with alginate, Carbohydrate Polymers 72 (2005) 334-341. 
[7] H. Türe, E. Eroğlu, B. Özen, F. Soyer, Antifungal activity of biopolymers containing natamycin and rosemary extract against Aspergillus niger and Penicillium roquefortii, International Journal of Food Science and Technology 43 (2008) 2026-2032.

[8] C.M.B.S. Pintado, M.A.S.S. Ferreira, I. Sousa, Control of pathogenic and spoilage microorganisms from cheese surface by whey protein films containing malic acid, nisin and natamycin, Food Control 21 (2010) 240-246.

[9] G-Q. Chen, F-P. Lu, L-X. Du, Natamycin production by Streptomyces gilvosporeus based on statistical optimization, Journal of Agricultural and Food Chemistry 56 (2008) 5057-5061.

[10] A. Reps, L. Jedrychowski, J. Tomasik, K. Wisniewska, Natamycin in ripening cheeses, Pakistan Journal of Nutrition 1 (2002) 243-247.

[11] P. Fajardo, J.T. Martins, C. Fuciños, L. Pastrana, J.A. Teixeira, A.A. Vicente, Evaluation of a chitosan-based edible film as carrier of natamycin to improve the storability of Saloyo cheese, Journal of Food Engineering 101 (2010) 349-356.

[12] T.M. Oliveira, N.F.F. Soares, R.M. Pereira, K.F. Fraga, Development and evaluation of antimicrobial Natamycin - incorporated film in gorgonzola cheese conservation, Packaging Technology and Science 20 (2007) 147-153.

[13] Y. Pranoto, S.K. Rakshit, V.M. Salokhe, Enhancing antimicrobial activity of chitosan films by incorporating garlic oil, potassium sorbate and nisin, LWT - Food Science and Technology 38 (2005) 859-865.

[14] A.C.S. Pires, N.F.F. Soares, N.J. Andrade, L.H.M. Silva, G.P. Camilloto, P.C. Bernardes, Development and evaluation of active packaging for sliced mozzarella preservation, Packaging Technology and Science 21 (2008) 375-383.

[15] M.A. da Silva, A.C.K. Bierhalz, T.G. Kieckbusch, Modelling natamycin release from alginate/chitosan active films, International Journal of Food Science and Technology 47 (2012) 740-746.

[16] M.E.M. Braga, M.T.V. Pato, H.S.R. Costa Silva, E.I. Ferreira, M.H. Gil, C.M.M. Duarte, H.C. de Sousa, Supercritical solvent impregnation of ophtalmic drugs on chitosan derivatives, The Journal of Supercritical Fluids 44 (2008) 245-257.

[17] V.P. Costa, M.E.M. Braga, J.P. Guerra, A.R.C. Duarte, C.M.M. Duarte, E.O.B. Leite, M.H. Gil, H.C. Sousa, Development of therapeutic contact lenses using a supercritical solvent impregnation method, The Journal of Supercritical Fluids 52 (2010) 306-316.

[18] A.M.A. Dias, M.E.M. Braga, I.J. Seabra, P. Ferreira, M.H. Gil, H.C. de Sousa, Development of natural-based wound dressings impregnated with bioactive compounds and using supercritical carbon dioxide, International Journal of Pharmaceutics 408 (2011) 9-19.

[19] P. Sonkaew, A. Sane, P. Suppakul, Antioxidant activities of curcumin and ascorbyl dipalmitate nanoparticles and their activities after incorporation into cellulose-based packaging films, Journal of Agricultural and Food Chemistry 60 (2012) 5388-5399.

[20] I. Kikic, F. Vecchione, Supercritical impregnation of polymers, Current Opinion in Solid State and Materials Science 7 (2003) 399-405.

[21] A.C.K. Bierhalz, M.A. da Silva, T.G. Kieckbusch, Natamycin release from alginate/pectin films for food packaging applications, Journal of Food Engineering 110 (2012) 18-25.

[22] M.A. Da Silva, B.T. Iamanaka, M.H. Taniwaki, T.G. Kieckbusch, Evaluation of the antimicrobial potential of alginate and alginate/chitosan films containing potassium sorbate and natamycin, Packaging Technology and Science (2012), http://dx.doi.org/10.1002/pts.2000.

[23] J. Crank, The Mathematics of Diffusion, second ed., Clarendon Press, Oxford, 1975.

[24] J.B. Xu, J.P. Bartley, R.A. Johnson, Preparation and characterization of alginate-carrageenan hydrogel films crosslinked using a water-soluble carbodiimide (WSC), Journal of Membrane Science 218 (2003) 131-146.

[25] ASTM, Standard Test Methods of Water Vapor Transmission of Material. Annual Book of ASTM Standards, American Society for Testing and Materials, Philadelphia, 1995, E 96-E95.

[26] ASTM, Tensile Properties of Thin Plastic Sheeting. Annual Book of ASTM Standards, American Society for Testing and Materials, Philadelphia, 1995, D 882.

[27] A.H. Thomas, Analysis and assay of polyene antifungal antibiotics, The Analyst 101 (1976) 321-339.
[28] P. Santiago-Silva, N.F.F. Soares, J.E. Nobrega, M.A.W. Junio, K.B.F. Barbosa, A.C.P. Volp, E.R.M.A. Zerdas, N.J. Wurlitzer, Antimicrobial efficiency of film incorporated with pediocin (ALTA_2351) on preservation of sliced ham, Food Control 20 (2009) 85-89.

[29] H. Türe, E. Eroğlu, B. Ozen, F. Soyer, Physical properties of biopolymers containing natamycin and rosemary extract, International Journal of Food Science and Technology 44 (2009) 402-408.

[30] M.J. Fabra, P. Talens, A. Chiralt, Microstructure and optical properties of sodium caseinate films containing oleic acid-beeswax mixtures, Food Hydrocolloids 23 (2009) 676-683.

[31] J. Kerč, S. Srčič, Ž. Knez, P. Senčar-Božič, Micronization of drugs using supercritical carbon dioxide, International Journal of Pharmaceutics 182 (1999) 33-39.

[32] R. Jayasekara, I. Harding, I. Bowater, G.B.Y. Christie, G.T. Lonergan, Preparation, surface modification and characterization of solution cast starch PVA blended films, Polymer Testing 23 (2004) 17-27.

[33] T. Çaykara, S. Demirci, M.S. Eroğlu, O. Güven, Poly(ethylene oxide) and its blends with sodium alginate, Polymer 46 (2005) 10750-10757.

[34] J-W. Rhim, J-H. Lee, S-I. Hong, Water resistance and mechanical properties of biopolymer (alginate and soy protein) coated paperboards, LWT - Food Science and Technology 39 (2006) 806-813.

[35] E. Kristo, K.P. Koutsoumanis, C.G. Biliaderis, Thermal, mechanical and water vapor barrier properties of sodium caseinate films containing antimicrobials and their inhibitory action on Listeria monocytogenes, Food Hydrocolloids 22 (2008) 373-386.

[36] M.A. da Silva, A.C.K. Bierhalz, T.G. Kieckbusch, Alginate and pectin composite films crosslinked with $\mathrm{Ca}^{2+}$ ions: effect of the plasticizer concentration, Carbohydrate Polymers 77 (2009) 736-742.

[37] K. Norajit, K.M. Kim, G.H. Ryu, Comparative studies on the characterization and antioxidant properties of biodegradable alginate films containing ginseng extract, Journal of Food Engineering 98 (2010) 377-384.

[38] D.S. Cha, M.S. Chinnan, Biopolymer-based antimicrobial packaging: a review, Critical Reviews in Food Science and Nutrition 44 (2004) 223-237.

[39] Y.-N. Phang, S.-Y. Chee, C.-O. Lee, Y.-L. The, Thermal and microbial degradation of alginate-based superabsorbent polymer, Polymer Degradation and Stability 96 (2011) 1653-1661.

[40] B. Sarmento, D. Ferreira, F. Veiga, A. Ribeiro, Characterization of insulin-loaded alginate nanoparticles produced by ionotropic pre-gelation through DSC and FTIR studies, Carbohydrate Polymers 66 (2006) 1-7.

[41] E.M. Zactiti, T.G. Kieckbusch, Release of potassium sorbate from active films of sodium alginate crosslinked with calcium chloride, Packaging Technology and Science 22 (2009) 349-358.

[42] J.A. Torres, M. Karel, Microbial stabilization of intermediate food surfaces III. Effects of surface preservative concentration and surface $\mathrm{pH}$ control on microbial stability of an intermediate moisture cheese analog, Journal of Food Processing and Preservation 9 (1985) 107-119.

[43] A. Redl, N. Gontard, S. Guilbert, Determination of sorbic acid diffusivity in edible wheat gluten and lipid based films, Journal of Food Science 61 (1996) 116-120.

[44] M. Ozdemir, J.D. Floros, Analysis and modeling of potassium sorbate diffusion through edible whey protein films, Journal of Food Engineering 47 (2001) 149-155.

[45] G.G. Buonocore, M.A. Del Nobile, A. Panizza, M.R.A. Corbo, A general approach to describe the antimicrobial release from highly swellable films intended for food packaging applications, Journal of Controlled Release 90 (2003) 97-107.

[46] L.R. Franssen, T.R. Rumsey, J.M. Krochta, Whey protein film composition effects on potassium sorbate and natamycin diffusion, Journal of Food Science 69 (2004) 347-350.

[47] S.K. Papageorgiou, E.P. Kouvelos, E.P. Favvas, A.A. Sapalidis, Metal-carboxylate interactions in metal-alginate complexes studied with FTIR spectroscopy, Carbohydrate Research 345 (2010) 469-473.

[48] M.A. Cerqueira, B.W.S. Souza, J.A. Teixeira, A.A. Vicente, Effect of glycerol and corn oil on physicochemical properties of polysaccharide films - A comparative study, Food Hydrocolloids 27 (2012) 175-184. 